\title{
O CAMPO DA COMUNICAÇÃO NO PENSAMENTO EDUCACIONAL DE CÉLESTIN FREINET: UMA ABORDAGEM COMPARADA
}

\author{
EL CAMPO DE LA COMUNICACIÓN EN EL PENSAMIENTO \\ EDUCATIVO DE CÉLESTIN FREINET: UN ENFOQUE COMPARATIVO
}

\author{
THE FIELD OF COMMUNICATION IN CÉLESTIN FREINET'S EDUCATIONAL \\ THINKING: A COMPARATIVE APPROACH
}

\author{
Cláudia Chaves FONSECA ${ }^{1}$ \\ Sandra Pereira TOSTA ${ }^{2}$
}

RESUMO: O artigo visa problematizar o campo da comunicação na obra de Célestin Freinet, analisando a inter-relação entre educação e comunicação no pensamento educacional do autor. Destaca-se nas obras do educador francês o entendimento da comunicação não somente como mídia - ainda que tenha sido um dos maiores divulgadores de técnicas pedagógicas como o jornal escolar - mas como uma perspectiva teórica e metodológica que edifica seu projeto educativo. O "comunicar-se" alinha-se ao "expressar-se", "criar, agir e compreender", "organizar-se" e "avaliar-se", de modo que a comunicação constitui-se em um eixo e uma finalidade da obra freinetiana. Trata-se de um recorte de tese, com previsão de defesa em março de 2017 , que estuda em perspectiva comparada o campo comunicacional como parte da matriz de pensamento na filosofia educacional de John Dewey, Célestin Freinet e Paulo Freire.

PALAVRAS-CHAVE: Comunicação. Mídia. Filosofia da educação. Educação comparada.

RESUMEN: El artículo pretende discutir el campo de la comunicación en el trabajo de Célestin Freinet, analizar la interrelación entre educación y comunicación en el pensamiento educativo del autor. Se destaca en los trabajos del educador francés la comprensión de la comunicación no sólo como medios de comunicación, incluso habiendo sido uno de los mayores divulgadores de técnicas pedagógicas como el periódico escolar-, sino como una perspectiva teórica y metodológica que construye su proyecto educativo. El "comunicarse" alineado al "expresarse", "crear, actuar y comprender", "organizarse" y "evaluarse", de modo que la comunicación se constituye en un eje y un propósito de la obra freinetiana. Se trata de un recorte de tesis, con previsión de defensa en marzo de 2017, que estudia en perspectiva comparada el

\footnotetext{
${ }^{1}$ Doutora pelo Programa de Pós-Graduação em Educação da Pontifícia Universidade Católica de Minas Gerais (PUCMinas). Jornalista e mestre em Comunicação pela Universidade Federal de Minas Gerais (UFMG). Professora e pesquisadora nas áreas de Educação e Comunicação. E-mail: claufon@gmail.com ${ }^{2}$ Doutora em Antropologia Social pela Universidade de São Paulo (USP). Mestre em Educação pela UFMG Jornalista pela PUCMinas. Professora e pesquisadora do Programa de Pós-Graduação em Educação da Pontifícia Universidade Católica de Minas Gerais (PUCMinas). E-mail: sandra@pucminas.br
} 
campo comunicacional como parte de la matriz del pensamiento sobre la filosofía educativa de John Dewey, Célestin Freinet y Paulo Freire.

PALABRAS CLAVE: Comunicación. Medios de comunicación. Filosofía de la educación. Eeducación comparada.

ABSTRACT: This article aims to problematize the field of communication in the work of Célestin Freinet by analyzing the interrelation between education and communication in the educational thinking of the author. In the works of the French educator he emphasizes the understanding of communication not only as a media although he was one of the greatest disseminators of pedagogical techniques such as the school newspaper - but also as a theoretical and methodological perspective that builds his educational project. "Communicating" is aligned with "expressing", "creating, acting and understanding", "organizing", and "evaluating", so that communication is an axis and purpose of Freine's work. The present work is part of a doctoral dissertation that is estimated to be defended in March 2017. This research presents in comparative perspective the communicational field as part of the matrix of thinking in the educational philosophy of John Dewey, Célestin Freinet, and Paulo Freire.

KEYWORDS: Communication. Media. Philosophy of education. Comparative education.

\section{Introdução}

A comunicação é um dos quatro eixos norteadores do pensamento educacional do pedagogo francês Célestin Freinet (1896-1966). Um dos autores mais originais do século XX, deixando um legado em que vida e obra entrelaçaram-se, Freinet destacouse pela formulação explícita de um problema pedagógico, bem como pela proposição de conceitos e técnicas para enfrentá-lo.

A biografia do autor, contada em detalhes por sua esposa Élise Freinet (18981983), nos livros Nascimento de uma pedagogia popular e O itinerário de Célestin Freinet, mostra-nos um educador que, a despeito da falta de formação universitária, soube como poucos empreender uma "leitura" do seu tempo - principalmente os difíceis anos entre guerras durante os quais viveu sua juventude - em termos da industrialização, urbanização acelerada, disseminação das tecnologias no cotidiano, modificação das mentalidades, perda de importância do discurso religioso, entre outros fatores. Freinet compreendeu que as alterações nos modos de vida, propiciados pelo desenvolvimento do capitalismo, impunham vastos desafios à educação básica. 
Na primeira etapa de sua jornada como professor primário, na aldeia de Bar Sur Loup, nos Alpes Franceses, o autor buscou alimento intelectual nas leituras de autores escolanovistas, como os suíços Adolf Ferrière (1879-1960) e Edouard Claparède (18731940), bem como o norte-americano John Dewey (1859-1952). Conheceu, também, por meio de leituras e viagens, a proposta pedagógica dos autores russos, tais como Pistrak (1888-1937) e Makarenko (1888-1939). A obra freinetiana, no entanto, destaca-se pela singularidade e pela utilização inovadora de técnicas pedagógicas.

O objetivo da tese da qual este artigo é um recorte é compreender como o campo da comunicação serve como matriz de pensamento para a formulação de uma filosofia da educação. No trabalho, realiza-se uma abordagem comparativa entre três autores: John Dewey, Célestin Freinet e Paulo Freire. Busca-se fazer uma hermenêutica do conceito de comunicação, perscrutando seus sentidos, examinando-o tanto dentro dos quadros de referência do campo de origem, quanto cotejando-o com os possíveis novos sentidos quando tratados por um outro campo, no caso, o educacional.

Longe de ser um conceito abstrato, a comunicação, no pensamento freinetiano, é uma forma de ação e uma técnica de vida (para usar um termo caro ao universo do autor), traduzida em atividades como a imprensa escolar, o livro da vida, a correspondência interescolar, o jornal mural, a biblioteca de trabalho, etc.

A partir de uma concepção materialista que expressa uma perspectiva política da comunicação, considerando este ato de modo concreto, em situações concretas por interlocutores determinados, Freinet valorizou a livre expressão infantil, elegendo o texto livre como a primeira forma de trabalho da criança. $\mathrm{O}$ texto livre será publicado por meio da imprensa (jornal) escolar.

$\mathrm{O}$ procedimento metodológico da tese foi, portanto, a pesquisa bibliográfica e documental. Após a localização, seleção e leitura da obra freinetiana, pretendeu-se, de forma processual, buscar no contexto espaço-temporal da produção do autor de que modos o conceito de comunicação é apresentado e desenvolvido por ele, e seus possíveis sentidos. A análise comparativa ${ }^{3}$ é feita por inferência, tendo em vista tanto a coerência interna de cada obra, como a coerência com a matriz de pensamento que a ampara e o contexto em que foi publicada.

\footnotetext{
${ }^{3}$ A perspectiva comparada é desenvolvida ao longo da tese. Como este artigo tem como foco somente a obra freinetiana, não se adota essa abordagem.
} 


\section{O campo comunicacional}

Se até mesmo a comunicação face a face apresenta diversas sutilezas e variáveis difíceis de compreender, a comunicação coletiva apresenta maiores desafios ao observador. O emprego atual do termo "comunicação" é complicado, inexato, uma vez que as situações de comunicação atingiram um grau enorme de presença e complexidade na vida cotidiana. A comunicação pode ser entendida como discurso, informação, técnica social ou processo, dependendo da situação e/ou circunstância em que ocorre.

A questão que emerge - como os homens se comunicam? - está associada ao fenômeno moderno da comunicação, justamente porque é uma pergunta no âmbito semiótico. Na história da espécie humana os indivíduos e grupos obviamente se comunicavam, mas não colocavam em dúvida o porquê, o como e com qual finalidade o faziam. A formulação dessas indagações coincide com a invenção da comunicação massiva.

A comunicação de massa é caracterizada pela onipresença tecnológica, pela separação espaço-temporal entre enunciador e enunciado, pelo desenvolvimento de grandes empresas voltadas ao entretenimento e orientadas pela lógica comercial (THOMPSON, 2009).

No início do século XX, quando a comunicação massiva passa a fazer parte do cotidiano, começa a surgir também um pensamento comunicacional, ou seja, uma reflexão científica sobre a comunicação. É nesse período, principalmente entre as duas guerras mundiais, que se inicia uma Teoria da Comunicação.

As primeiras teorias da Comunicação foram formuladas nos Estados Unidos e se guiavam por um paradigma que postulava a transmissão de informação como modelo comunicacional. $\mathrm{O}$ ato comunicativo era percebido como uma transmissão, usando para ilustrar essa concepção a imagem da ligação telefônica: um emissor codifica uma mensagem e, por meio de um canal (o telefone), a enviaria para um receptor. Tal forma de explicar a comunicação como troca de informação, que inclusive pode ser mensurada em sua eficácia, confere maior importância ao aspecto técnico.

A partir dos anos sessenta do mesmo século, os estudos foram reorientados em direção a uma concepção não era mais entendida como um dado, mas sim como um processo. De acordo com Wolf (1994, p.126): 
Isto é, realça-se o caráter processual da comunicação, que é analisada quer na sua dinâmica interna, quer nas suas relações com outros processos comunicativos, anteriores ou contemporâneos [...] Evidencia-se a interação e a interdependência permanentes dos fatores que entram em jogo no processo de influência.

Essa "virada" epistemológica muito deveu aos aportes da Antropologia, da Semiótica e da Psicologia Social, que trouxeram uma perspectiva relacional aos estudos comunicacionais.

A comunicação, de acordo com o paradigma relacional, é um processo ativo, no qual interlocutores constroem sentidos intersubjetivamente, de modo que não se pode falar em um resultado - mas numa circulação social de signos. Por esse modo de pensar, a comunicação coletiva, mesmo com a lógica do poderio econômico e político que a conforma, não seria capaz de massificar completamente o público, uma vez que a inserção nos contextos culturais promove uma negociação permanente do sentido.

\section{Educação e Comunicação em Freinet}

Na obra de Freinet, o campo da comunicação ocupa um lugar destacado, uma vez que sua trajetória como educador sempre esteve intimamente associada às mais diversas modalidades e expressões comunicacionais. Um dos princípios que regem a práxis freinetiana é o da livre expressão, encarnado, em primeira instância, pelo texto livre.

Esta técnica é "a expressão natural inicial da vida infantil no seu ambiente normal”, conforme definiu Freinet (1976) e se constitui no fundamento das demais técnicas de vida desenvolvidas nas classes freinetianas.

Um texto livre é, como a sua designação indica, um texto que a criança escreve livremente, quando tem o desejo de fazê-lo, em conformidade com o tema que a inspira. Não é aconselhável, por conseguinte, a imposição de um assunto, nem se deve estabelecer um plano destinado ao que se tornaria então uma espécie de exercício de texto livre que, como é óbvio, constituiria apenas uma redação de tema livre (FREINET, 1976, p. 60).

Em oposição à tradicional redação escolar - tarefa em que o aluno recebe um tema e a indicação do número de linhas para desenvolvê-lo - o texto livre não é uma 
tarefa, mas a maneira pela qual o aluno pode traduzir em palavras (e desenhos) suas vivências, pensamentos e emoções, sem predeterminações de forma e/ou estilo.

Os princípios que regem o texto livre estão ligados aos três grandes aspectos, de acordo com Fortunato (2016) do arcabouço teórico freinetiano: a noção de "bom senso", a psicologia sensível e o método "natural" de aprendizagem.

O "bom senso" que "poderia ser referido como algo parecido com uma educação para a vida" (FORTUNATO, 2016, p.178) alicerça o texto livre quando não submete a escrita do aluno a um tema preestabelecido, um tema "escolar". O aluno escreve sobre a realidade vivida, sobre suas experiências cotidianas, aquilo que lhe é familiar.

Ao deixar fluir suas emoções por meio do texto, o aluno simultaneamente se expressa e se organiza interiormente. Este aspecto vincula-se à psicologia sensível preconizada por Freinet que "diz respeito à compreensão da vida por uma perspectiva que não é a da racionalidade" (FORTUNATO, 2016, p. 178).

O texto livre é um texto processual, que vai evoluindo conforme o aluno se sente mais confiante ao expressar-se. "É a própria criança que, apesar do meio, corrige audaciosamente, pouco a pouco, não se sabe ainda bem por que misterioso trabalho, as formas imperfeitas", explicou Freinet (1977, p. 45). O aluno utiliza um procedimento tateante, próprio do método "natural", em que o aprendiz vai adquirindo por tentativa e erro, o conhecimento, a partir de suas vivências, de maneira não-rígida.

Para Freinet (1973), que lecionou para crianças do meio rural, com inúmeras carências econômicas e culturais, a questão da expressão livre evidencia o caráter político de sua proposta pedagógica, qual seja, o de valorizar o universo cultural do aluno, ao mesmo tempo abrindo-lhe as portas para horizontes culturais mais amplos. A expressão, no texto escrito, é de natureza pública. "O texto livre libera o pensamento da criança, facilita sua expressão, está na origem da literatura infantil autêntica" (FREINET, 1979, p.31). A radicalidade dessa abertura é tanta que o texto livre, para o autor, poderia substituir os manuais, as provas e as avaliações escolares.

Por que o uso do adjetivo "livre"? Além, obviamente, da liberação dos rituais "escolásticos", tais como a recitação, a cópia e o ditado, como dizia Freinet (1977), o conceito de liberdade refere-se ao abandono do autoritarismo no meio escolar. O texto livre não é um texto encomendado pelo professor em troca de nota, é um texto expressão do vivido, das emoções. O autor afirmou seu sentido revivificador: "temos de dar um sentido afetivo e humano aos textos lidos e escritos" (FREINET, 1977, p. 33). 
A livre expressão e o texto livre ensejam a formação sadia da personalidade infantil: "é exprimindo-nos que aprendemos a exprimir-nos, a tomar consciência de nós mesmos, a afirmar a nossa personalidade" (FREINET, 1977, p. 44).

O conceito de liberdade relaciona-se às várias situações concretas da vida infantil, como a relação com a família, com a escola e com a comunidade mais próxima. Oliveira comenta a esse respeito:

Não existe liberdade abstrata, anterior à inserção do indivíduo no mundo. Só existe liberdade em se fazendo, em se construindo, numa situação concreta de vida. O que torna um trabalho ou um texto livre para as crianças concretas da escola pública, para os filhos das classes populares, é em primeiro lugar, a possibilidade de dizer sua concepção de mundo, em oposição àquela veiculada pelo ensino oficial. É poder refletir sobre essas visões opostas e fazer desta reflexão uma arma em favor da sua libertação: texto livre, texto libertador (OLIVEIRA, 1995, p. 148).

O texto livre evolui conforme o aluno vai descobrindo que pode expressar-se e que consegue dominar os recursos para isso. $\mathrm{O}$ aluno sente que o texto não é feito para $\mathrm{o}$ professor, mas para ele mesmo, enquanto membro de uma sociedade (representada, na escola, pelos colegas de classe e pelos alunos e professores das outras classes com os quais trocam correspondência). Não é preciso que o professor tenha pressa em corrigir os erros gramaticais, uma vez que quando a comunicação é autêntica, o próprio aluno tem a necessidade de aperfeiçoar-se, responsabilizando-se por sua criação literária: " $O$ essencial é que a criança sinta o valor, o sentido, a necessidade, o alcance individual e social da escrita-expressão.’(FREINET, 1973, p.55).

A aprendizagem da escrita e da leitura na proposta freinetiana está, portanto, para bem mais além do âmbito escolar, inserindo-se num contexto social de comunicação. O texto é um produto social e na sociedade vai circular. A partir de 1924, em Bar Sur Loup, os alunos de Freinet passaram a trocar cartas e encomendas com alunos de outras escolas francesas e do continente europeu. Essa técnica foi adotada pelo movimento Freinet. Do mesmo modo, o "livro da vida" é um álbum confeccionado pelas próprias crianças, no qual elas montam seus textos livres, desenhos e tudo o mais que considerem importante em determinado ano letivo. Esse livro tem como finalidade principal documentar a trajetória de aprendizagem e de descobertas dos alunos.

Daí a importância da correspondência interescolar, do livro da vida e da imprensa escolar como técnicas da escola francesa moderna. 


\section{A afirmação da cidadania infantil}

Nos primeiros anos de sua carreira como professor, Freinet utilizou-se de um tipógrafo para imprimir os textos livres. As próprias crianças aprenderam a manejar a máquina, que se mostrou excelente recurso para a alfabetização dos alunos. O tipógrafo também ampliou o alcance da escrita, o texto podia ser enviado pelo correio a um número maior de leitores (os correspondentes) uma vez que o texto livre escrito à mão ficava restrito à escola e à família (FREINET, 1977).

O tipógrafo ampliou a possibilidade de dar à escrita a característica de produto social. O impresso funciona, em nossa cultura ocidental, como uma forma de fixação da palavra, separando o enunciador do enunciado, conferindo ao conteúdo escrito uma aura de veracidade. A esse aspecto da técnica Freinet, Oliveira comenta:

o objetivo de todo esse processo é, mantendo a ideia central do autor, torna-la mais precisa, enriquecê-la, completa-la. O texto passa a ser o texto de todos, sem que, contudo, lhe sejam tiradas as características pelas quais seu autor o sente como seu, reflexo de sua individualidade (OLIVEIRA, 1995, p. 151)

Em meados da década de 1920, Freinet inicia, então, seu trabalho com o jornal escolar: "uma coletânea de textos livres das crianças, expressão fiel dos interesses maiores da turma e do seu meio" (FREINET, 1976, p.18).

O autor inspirou-se, para desenvolver a técnica do jornal escolar, no pedagogo belga Decroly (1871-1932), que já no final da Primeira Guerra Mundial havia publicado um jornal em sua escola. Freinet alerta, na introdução de seu primeiro livro $O$ Jornal Escolar (1927), que não se pode considerar qualquer experiência de jornal na escola como jornal escolar. Para tanto, é preciso que a técnica se insira numa perspectiva pedagógica da escola do trabalho e, em virtude do alcance dessa proposta, o autor dedicou a vida ao seu esclarecimento, aperfeiçoamento e divulgação, conforme afirma no trecho abaixo:

O jornal escolar é uma 'produção', uma obra ao alcance das nossas classes e que toca profundamente no essencial da nossa vida educativa. Põe-nos no caminho de uma fórmula nova de escola, aquela escola do trabalho cuja necessidade começamos a sentir, que já não trabalha segundo normas intelectualizadas, mas sim com base numa atividade social (FREINET, 1976, p.86).

O jornal escolar não seria necessariamente informativo, objetivo, tal como os jornais destinados ao público adulto. O sentido da afetividade guiaria a publicação: "a 
vida da criança, as suas reações perante o mundo, as suas hesitações, os seus temores e o seus triunfos." (FREINET, 1976, p.57). De acordo com cada faixa etária, o jornal se desenvolveria em forma e conteúdo, mas um de seus benefícios seria, justamente, a liberação psíquica da criança, um canal de expressão dos sentimentos e ideias. A autoconfiança adquirida com a produção do jornal reforçaria o valor social da criança.

A técnica do jornal escolar, aos olhos de Freinet, possuía uma dupla finalidade: dar concretude ao esforço de escrita do aluno, fazendo-o redigir o texto para um destinatário, marcando o papel social da escrita; ao mesmo tempo em que poderia desmistificar, para a classe, a palavra impressa, o poder do jornal escrito pelas classes hegemônicas. $\mathrm{O}$ autor, ele mesmo oriundo de classes populares, entendia como muito importante despertar a criticidade do aluno frente ao texto impresso, que à primeira vista exercia fascínio porque estava longe da realidade cotidiana dos alunos, que não tinham acesso e, consequentemente, nenhuma familiaridade com meios impressos. O jornal, uma das formas do impresso, é um instrumento essencial na comunicação coletiva nas sociedades modernas, mas nem por isso deve ser reificado ou sacralizado:

Uma das grandes deficiências da nossa cultura - e a escola teve pelo menos participação nela - é o caráter de tabu que o impresso assume para as crianças e aos adultos da nossa época. O jornal, principalmente, é tabu. Está escrito!... Está impresso! Não estaria no jornal se fosse falso! (FREINET, 1976, p.110)

\section{A comunicação como elemento dialético na dinâmica socioeducativa}

Freinet adota uma perspectiva relacional da comunicação recusando, em suas obras, qualquer forma de autoritarismo aberta ou velada. A horizontalidade que vislumbra para as relações humanas é construída por meio do trabalho cooperativo, num ambiente que reconcilia razão e afetividade. Em alguns pontos de sua obra, principalmente nos últimos livros, nos quais se destaca uma perspectiva mais vitalista, o autor tende a valorizar o meio natural como ideal educativo. Essa reflexão é importante, porque nos ajuda a compreender a relação entre educação e comunicação na obra freinetiana.

O autor se oporá à ciência e às técnicas modernas sempre que forem veículos de discriminação e não de cooperação, de morte e não de vida, de arbitrariedade e não de harmonia, de submissão e não de liberdade. (NASCIMENTO, 1995, p. 40). 
Em seus livros, Freinet por vezes parece adotar um posicionamento ambíguo sobre os meios de comunicação coletiva. Se nos detivermos mais cuidadosamente em seu pensamento, verificamos que o pedagogo busca examinar dialeticamente a tecnologia comunicacional na sociedade contemporânea. Ela tanto pode exercer uma influência consumista, ideológica, "embrutecedora" - nas palavras do autor - como também ter uma potencialidade emancipatória. A utilização dos meios de comunicação na escola nunca é gratuita, revela-se um ato pedagógico e político intencional. Freinet lança uma importante questão sobre as relações entre a escola e o meio:

Em que medida é que a educação periescolar auxilia a ação da escola? Há a máxima necessidade de se ter em conta a influência da família em regime capitalista, e a influência de todas as forças obscurantistas cujos esforços se conjugam no sentido da manutenção de uma ordem social única: o cinema, o rádio, a imprensa - com os seus jornais para crianças e seus livros alienatórios para adultos - os seus livros de cordel e as suas revistas malsãs (...) (FREINET, C. apud FREINET, E., 1978, p. 281 $)^{4}$

Em resposta à questão por ele mesmo formulada, Freinet não foge à contradição colocada pela presença dos meios de comunicação na sociedade, convocando os professores a enfrenta-la:

Apesar de todas as forças reacionárias e contra elas, os professores primários devem erguer o seu protesto na sua dupla condição de cidadãos e de educadores decididos a integrar completamente a sua tarefa no processo histórico da evolução social (FREINET, C. apud FREINET, E., 1978, p. 281).

Para Freinet, os meios de comunicação são tecnologias inventadas com o sentido preciso de distração, de alienação dos problemas colocados pelo modo de vida capitalista. Os meios audiovisuais como o rádio, o cinema e a televisão, por representarem um aperfeiçoamento desse tipo de tecnologia, precisam ser vistos com mais cuidado ainda. Por isso, cabe ao educador exercer a intencionalidade pedagógica, reconhecendo a presença dos meios e sua importância na vida das crianças, mas ao mesmo tempo exercendo uma crítica sobre eles, numa visão emancipatória. Ao comentar sobre o rádio escolar, por exemplo, disse o autor:

Também nos agrada constatar que as emissões de rádio vão passar de simples distrações que são para autênticas lições. Apenas se trata de

${ }^{4}$ No livro Nascimento de uma pedagogia popular (1978) a esposa de Freinet, Èlise, reproduz vários escritos do marido sem citar precisamente a fonte. Por isso a citação de citação destes trechos. 
um outro tipo de lições que terão que ser concebidas de acordo com uma nova técnica. Essa técnica é a que nós preconizamos e preparamos. Não teremos dificuldade em completar os elementos de estudo que nos trazem as 'ondas escolares' graças ao nosso ficheiro e à nossa biblioteca de trabalho. É aí que se revela a importância e a necessidade destes novos utensílios (grifo nosso) (FREINET, C. apud FREINET, E., 1978, p. 407).

Freinet ao refletir sobre a imprensa e os meios de comunicação audiovisuais, demonstrou perspicácia na compreensão do lugar e do movimento dessas técnicas no mundo atual. Percebeu o quanto a disseminação dos meios de comunicação de massa se constituiu em um elemento central ao desenvolvimento do capitalismo, embora utilizando-se de estratégias como a sedução do público para distraí-lo e aliená-lo. A esse efeito sobre as consciências, podemos recorrer ao termo "efeito haxixe", próprio do vocabulário freinetiano, que foi utilizado pelo autor para descrever o "amortecimento" que os meios de comunicação impõem ao público.

Por outro lado, o educador francês teve a ousadia de pensar pedagogicamente a utilização desses mesmos meios de comunicação, uma vez que fazem parte do mundo e da vida da criança:

É obvio que não preconizamos a Imprensa Escolar unicamente como processo técnico de impressão de textos úteis à leitura global. O que nós pretendemos é que a vida das crianças passe realmente para o centro da aula através da Imprensa Escolar e que se abandonem definitivamente todos os exercícios escolásticos novos ou antigos, que serão proveitosamente substituídos pela atividade alegre e livre (FREINET, C. apud FREINET, E., 1995, p.195).

O trecho acima confirma que o conceito de técnica freinetiana como parte que, embora tenha finalidade nela mesma, converge com outras para uma finalidade maior, guiada por uma perspectiva política da educação. A vida "real" das crianças deve ser o centro da escola e não o próprio jornal, mas sem este não se alcança aquela.

É importante considerar, como o fez o próprio Freinet, que a técnica da imprensa, do rádio e do cinema escolar são flexíveis, as maneiras de se trabalhar com esses meios (e os próprios meios) se transformam historicamente. Embora alguns seguidores de Freinet leiam de modo um tanto rígido sua obra, priorizando o trabalho com o jornal escolar, atualmente as mídias digitais como, por exemplo, computadores e telefones celulares abrem um universo vastíssimo de possibilidades de interação entre 
educação e comunicação. A internet, tão presente na vida atual, pode ser trabalhada como potência e recurso educativo, por meio das mídias sociais, dos jogos, dos aplicativos de mensagens, entre outros.

É a finalidade política, na mais ampla acepção deste termo, que oferece a medida da educação, para Freinet:

\begin{abstract}
A educação das crianças não pode ser uma exceção no processo vivo do progresso humano (...) $\mathrm{O}$ essencial é que saibamos para onde vamos; que distingamos as forças essenciais e permanentes que devemos mobilizar e que aperfeiçoemos paciente, metódica e cooperativamente os utensílios de trabalho que nos hão-de trazer excelentes colheitas humanas (FREINET, C. apud FREINET, E., 1995, p. 195).
\end{abstract}

Dessa forma, a comunicação é eixo da pedagogia freinetiana porque está no mundo, é força viva, espaço de contradição que tanto pode levar à emancipação quanto à alienação.

\title{
Considerações finais
}

Não se compreende a obra educacional de Célestin Freinet sem a perspectiva comunicacional que adota. Isso porque, a comunicação torna-se um eixo/pilar no pensamento de Freinet à medida que se alinha com o trabalho como princípio pedagógico. A escola é o trabalho da criança e nela são vivenciados, numa perspectiva crítica, os elementos da realidade extraescolar. Os meios de comunicação são um deles.

Observamos que Freinet pensava com lucidez a questão da comunicação em seu tempo, mas suas contribuições continuam atuais. Do mesmo modo em que percebia as vantagens e a facilidade que os meios de comunicação (em um primeiro momento, o jornal, mas depois os meios audiovisuais) traziam para a vida cotidiana, também reconhecia seu papel persuasivo, tornando-se um poder simbólico fundamentado pelo registro da palavra. $\mathrm{O}$ autor alertava para o perigo de tais recursos serem apropriados por uma pequena parcela da sociedade, que o utilizariam para perpetuar as desigualdades sociais.

Por isso, a técnica do jornal escolar precisa ser muito bem compreendida na pedagogia Freinet, pois não se trata de uma apologia aos meios de comunicação ou a introdução de uma "novidade" na sala de aula. Para o pedagogo, o jornal é uma ferramenta para se exercitar a dialogicidade na comunicação, que ficaria restrita ao 
interpessoal se confinada apenas às paredes da sala de aula. $\mathrm{O}$ uso do jornal tem um sentido político-pedagógico preciso, que é o de erigir o cidadão:

No dia em que os cidadãos souberem que o seu jornal pode mentir, ou pelo menos, apresentar como definitivas soluções que são apenas um aspecto parcial dos problemas impostos pela vida, quando estiverem aptos a discutir com prudência, mas também com ousadia, quando tiverem essa formação de experimentadores e criadores que nos esforçamos por lhes dar, haverá então qualquer coisa de diferente nas nossas democracias (FREINET, 1976, p.112).

O trecho acima sugere que Freinet vislumbrava um papel de resistência para o jornal escolar. Quando elabora o texto impresso e se apropria de todas as suas etapas, a criança percebe que a palavra não é privilégio de alguns e que ela também tem o direito de expressar-se.

A troca simbólica promovida pela comunicação coletiva ampara-se na separação entre enunciador e enunciado tanto no tempo como no espaço, de tal forma que a mensagem parece ser autossuficiente. A mensagem midiática, como percebeu Freinet, ganha dessa forma uma impressão de realidade, muitas vezes ideologizada. Esse é o ponto nodal que a proposta do autor quer problematizar.

Há, porém, outra característica da comunicação escrita que é igualmente importante: é uma forma de testemunho, de documentação. E a passagem do tempo fará o necessário contraste entre as muitas versões testemunhais. Por isso o pedagogo francês tanto insistiu no valor da expressão escrita.

Para Freinet, o jornal escolar é a "medida da escola". Ele une a teoria à prática de tal modo que o aprendizado pode ser avaliado, não apenas pelo professor, mas também pelo aluno e suas famílias, na medida em que são leitores e debatem os temas. O jornal escolar é um produto, mas não um dado: funciona como espelho de um lento processo cotidiano de trabalho pedagógico. Não é simplesmente um objeto, uma "coisa", mas a materialização do sucesso escolar:

E contudo é necessário que a escola afirme a sua fecundidade produzindo uma obra que não seja exclusivamente abstrata, mas também não apenas material, que esteja imbuída de uma suficiente espiritualidade para autenticar a sua função eminente (FREINET, 1976, p. 85).

O jornal escolar, como técnica Freinet, une-se a outras técnicas desenvolvidas pelo autor", como "ferramentas" que, testadas na prática, revelam as contradições do

${ }^{5}$ Citamos, como exemplo, a Biblioteca de Trabalho e o Fichário Escolar. 
fazer pedagógico, uma vez que exigem do professor uma postura colaborativa, nãoimpositiva, mas nunca descuidada ou descomprometida Cada uma das técnicas busca um sentido, mas todas se unem na perspectiva télica do autor: a educação para a transformação sócio-política.

A técnica do jornal escolar precisa ser muito bem compreendida na pedagogia Freinet, pois não se trata de uma apologia aos meios de comunicação ou a introdução de uma "novidade" na sala de aula. Para o pedagogo francês, o jornal é uma ferramenta para se exercitar a dialogidade na comunicação, que ficaria restrita ao interpessoal se confinada apenas às paredes da escola. $\mathrm{O}$ uso do jornal tem um sentido políticopedagógico preciso, o de erigir a cidadania infantil.

Dessa forma, a comunicação é eixo da pedagogia freinetiana porque está no mundo, é força viva, espaço de contradição que tanto pode promover a autonomia quanto a alienação.

\section{Referências}

FORTUNATO, Ivan. 50 anos sem Célestin Freinet, 500 anos de retrocesso das práticas escolares. Journal for Educators, Teachers and Trainers, JETT, Vol.7 (1); 174-181, 2016.

FREINET, Célestin. Para uma escola do povo: guia prático para a organização material, técnica e pedagógica da escola popular. Lisboa: Presença, 1973.

FREINET, Célestin. O jornal escolar. Lisboa: Estampa, 1976.

FREINET, Célestin; BALESSE, Luciene. A leitura pela imprensa na escola. Porto: Dinalivros, 1977.

FREINET, Élise. Nascimento de uma pedagogia popular: os métodos Freinet. Lisboa: Estampa, 1978.

FREINET, Élise. O itinerário de Célestin Freinet: a livre expressão na pedagogia Freinet. Rio de Janeiro: Francisco Alves, 1979.

NASCIMENTO, Maria Evelyna. A pedagogia Freinet: natureza, educação e sociedade. Campinas/SP: Editora da UNICAMP, 1995.

OLIVEIRA, Anne Marie Milon. Célestin Freinet: raízes sociais e políticas de uma proposta pedagógica. Rio de Janeiro: Papéis e Cópias de Botafogo, 1995.

THOMPSON, John. A mídia e a modernidade. Petrópolis: Vozes, 2009. 
WOLF, Mauro. Teorias da Comunicação. $3^{\text {a }}$. ed. Lisboa: Presença, 1994.

\section{Como referenciar este artigo}

FONSECA, Cláudia Chaves.; TOSTA, Sandra Pereira. O campo da comunicação no pensamento educacional de Célestin Freinet: uma abordagem comparada. Revista Ibero-Americana de Estudos em Educação, Araraquara, v. 12, n. esp. 1, p.629-643, 2017. Disponível em: <http://dx.doi.org/10.21723/riaee.v12.n.esp.1.2017.9668>. EISSN: 1982-5587.

Submetido em: 20/03/2017

Aprovado em: 11/04/2017 